\title{
EFFICACY AND SAFETY OF LABETALOL IN THE MANAGEMENT OF MODERATE GESTATION HYPERTENSION - A PROSPECTIVE OBSERVATIONAL STUDY
}

\author{
Asharani A. Kanaki ${ }^{1}$, Anand R. Kanaki ${ }^{2}$, Nirmala Rampure 3 , Gangambika M. Nisty 4 \\ ${ }_{1}^{1}$ Post Graduate Student, Department of Obstetrics and Gynaecology, MRMC. \\ ${ }^{2}$ Associate Professor, Department of Pharmacology, MRMC. \\ ${ }^{3}$ Professor, Department of Obstetrics and Gynaecology, MRMC. \\ ${ }^{4}$ Professor \& HOD, Department of Obstetrics and Gynaecology, MRMC.
}

\begin{abstract}
Hypertensive disorders are the most common medical disorders in pregnancy contributing significantly to maternal and perinatal mortality and morbidity worldwide. The incidence is around 3-10\% of all pregnancies. Antihypertensive drugs are often used to lower blood pressure with the aim of preventing its progression to adverse outcomes for the mother, at the same time they should not have adverse effects on the uteroplacental circulation and the fetus. The risk of developing severe hypertension is reduced to half by using antihypertensive medications. The objective of this study is to study efficacy and safety of Labetalol in lowering blood pressure in patients with moderate gestational hypertension.
\end{abstract}

\section{METHOD}

This is a prospective observational study where fifty six pregnant patients with moderate gestational hypertension on labetalol are included in the study. Reduction in hypertension and frequency of side effects were studied. The statistical level of significance was taken at $\mathrm{P}<0.05$.

\section{RESULT}

The result showed labetalol is effective in control of blood pressure and well tolerated with free of side effects.

\section{CONCLUSION}

Labetalol is a safe, well tolerated and effective in controlling blood pressure in moderate gestational hypertension.

\section{KEYWORDS}

Moderate Gestational Hypertension, Labetalol.

HOW TO CITE THIS ARTICLE: Kanaki AA, Kanaki AR, Rampure N, et al. Efficacy and safety of labetalol in the management of moderate gestation hypertension - a prospective observational study. J. Evolution Med. Dent. Sci. 2016;5(41):2531-2534, DOI: $10.14260 /$ jemds/2016/591

\section{INTRODUCTION}

Hypertensive disorders of pregnancy are an important cause of severe morbidity and mortality among both mother and fetus. ${ }^{1}$ Hypertensive disorders of pregnancy are classified into 4 categories Chronic hypertension, Preeclampsia-eclampsia, Preeclampsia superimposed on chronic hypertension and Gestational hypertension (transient hypertension of pregnancy or chronic hypertension identified in the latter half of pregnancy). ${ }^{2}$ Hypertensive disorders of pregnancy are common in developing countries like India. Hypertensive disorders seem to complicate approximately $10 \%$ of pregnancies and are important causes of maternal and fetal morbidity and mortality. ${ }^{3}$ International guidelines define severe pregnancy hypertension as systolic blood pressure (SBP) $\geq 160-170 \mathrm{mmHg}$ and/or diastolic BP (DBP) $\geq 110$ mmHg.4,5 Severe hypertension is the only modifiable endorgan complication of pre-eclampsia, the most dangerous of the hypertensive disorders of pregnancy. ${ }^{6}$ It is widely accepted that women with severe hypertension are at increased risk of stroke and as such must have their BP lowered.7,8

Financial or Other, Competing Interest: None.

Submission 01-04-2016, Peer Review 02-05-2016,

Acceptance 07-05-2016, Published 23-05-2016.

Corresponding Author:

Dr. Asharani A. Kanaki,

Post Graduate Student,

Department of Obstetrics and Gynaecology,

M. R. Medical College,

Sedam Road, Gulbarga-585105.

E-mail:anandkanaki@yahoo.com

DOI: $10.14260 /$ jemds/2016/591
The hypertensive disorders of pregnancy are very important disorders, because if not treated they may adversely affect both the mother and the fetus. ${ }^{9,10}$ They predispose to acute or chronic uteroplacental insufficiency that may lead to fetal death, Intrauterine Growth Retardation (IUGR) and preterm delivery.11 It is proven that control of hypertension reduces these complications. ${ }^{12,13}$

All international pregnancy hypertension guidelines recommend immediate treatment of severe pregnancy hypertension, a recommendation endorsed as 'strong' by the World Health Organization (WHO). ${ }^{14}$ While severe pregnancy hypertension is a 'hypertensive urgency' that requires treatment, it is appropriate to lower BP over hours (and certainly within 24 hours) and this could be achieved with oral or parenteral antihypertensive therapy. Traditionally, severe hypertension has been treated with short-acting parenteral antihypertensive agents, most frequently, intravenous hydralazine or labetalol.15,16,17 These agents have been most widely studied in Randomized Controlled Trials (RCTs), although systematic reviews have failed to reveal clear differences between agents. ${ }^{18,19}$

Once blood pressure rises above a certain level; however, there is a risk of direct damage to the blood vessel wall, regardless of what caused the rise. This risk is not specific to pregnancy, as it is similar for non-pregnant people with very high blood pressure. The level at which this risk merits mandatory antihypertensive therapy is usually considered to be $170 \mathrm{mmHg}$ systolic blood pressure or $110 \mathrm{mmHg}$ diastolic. ${ }^{20}$ If the woman has signs and symptoms associated with severe pre-eclampsia (such as hyperreflexia, severe 
headache, sudden onset of epigastric pain or lowered platelets), a lower threshold for treatment may be recommended. ${ }^{21}$ The possible consequences of such high blood pressure for the mother include kidney failure, liver failure and cerebrovascular haemorrhage (stroke).

In the UK, for example, stroke resulting from severe hypertension was the single most common cause of maternal death associated with preeclampsia. For the baby, risks include fetal distress due to impaired blood supply across the placenta and placental abruption (separation of the placenta from the wall of the womb before birth).

The commonly used antihypertensive drugs in pregnancy are Nifedipine, methyldopa, labetalol and hydralazine.22,23 Most of these drugs are quite safe for mother and foetus. ${ }^{24}$

In pregnancy, mild hypertension means diastolic blood pressure 90-99 $\mathrm{mmHg}$, systolic blood pressure 140-149 mmHg. Moderate hypertension means diastolic blood pressure 100-109 $\mathrm{mmHg}$, systolic blood pressure 150-159 mmHg. And severe hypertension means diastolic blood pressure $110 \mathrm{mmHg}$ or greater, systolic blood pressure 160 mmHg or greater. ${ }^{25}$ According to National Collaborating Centre for Women's and Children's Health (NICE) guidelines, antihypertensive treatment is not needed in mild hypertension, but need to be given in all cases of moderate-tosevere hypertension. 26,27

A prospective study conducted in 2012 evaluated the effectiveness and safety of oral Labetalol and oral Nifedipine in pregnant women with Pregnancy Induced Hypertension (PIH) and concluded that Labetalol is more effective than Nifedipine in controlling blood pressure, whereas tachycardia (11\%) and occipital headache are more common with Nifedipine. ${ }^{13}$

Hence, the present study focuses on an assessment of efficacy and safety of Labetalol in lowering blood pressure in patients with moderate gestational hypertension.

\section{MATERIALS AND METHODS}

The study was a prospective observational study conducted at Basaweshwara Teaching and General Hospital attached to M.R. Medical College, Kalaburagi. Ethical clearance was obtained from Ethics Committee, M.R. Medical College, Kalaburagi.

\section{Inclusion Criteria}

All pregnant patients with systolic blood pressure in range of 150 to $159 \mathrm{mmHg}$ and a diastolic blood pressure in range of 100 to $109 \mathrm{mmHg}$ on two occasions four hours apart after 20 weeks of gestation attending OBG Department, Basaweshwara Teaching and General Hospital between July 2015 to December 2015.

\section{Exclusion Criteria}

1. PIH with preeclampsia/eclampsia.

2. Heart diseases including IHD.

3. Haematological disorders.

4. Liver diseases.

5. History of intolerance/hypersensitive to Labetalol.

The criteria for entry into the study was a sitting systolic blood pressure range of 150 to $159 \mathrm{mmHg}$ and a diastolic blood pressure (disappearance of sounds phase V, Korotkoff sounds) in range of 100 to $109 \mathrm{mmHg}$ on two occasions at least
4 hours apart. On each occasion, the mean of two readings taken one minute apart after the patient had been sitting quietly for 10 minutes was recorded. All patients were managed as per National Institute for Health and Clinical Excellence (NICE) 2011 revised guidelines for the management of hypertensive disorders during pregnancy.

The study group consists of 118 pregnant patients selected on the basis of inclusion and exclusion criteria with moderate gestational hypertension. Labetalol in the dose of $100 \mathrm{mg}$ BD. Detailed medical and obstetric history was taken along with complete obstetric examination. Blood pressure was recorded using Mercury Sphygmomanometer. All outpatients were seen week after starting treatment with Labetalol $100 \mathrm{mg}$ BD and then one month after starting treatment. Side effects of the drugs were also recorded during study period. The primary outcome was successful control of SBP $<150 \mathrm{mmHg}$ and DBP $<100 \mathrm{mmHg}$ without using additional drugs. Secondary outcomes included maternal side effects such as hypotension, headache, flushing, nausea and vomiting, dizziness or cardiovascular accidents after starting the antihypertensive medication.

\section{STATISTICAL ANALYSIS}

For parametric data, Student's t-test and Chi-square goodnessof-fit tests were used, whereas for non-parametric data RIDIT analysis was used.

\section{RESULTS}

Out of 117 patients, 6 patients were excluded from the study because they failed to comply regular followup. Further analysis will focus on the 111 patients who completed the study.

In the present study, about $15.31 \%$ of the pregnant women were primigravidae. The rest of the patients were multigravidae.

\begin{tabular}{|c|c|}
\hline Comparison or Outcome & Mean \\
\hline Age (Years) & $24.23 \pm 3.64$ \\
\hline Primi's & 17 \\
\hline Weight (kg) & $55.56 \pm 2.28$ \\
\hline Gestational age at enrolment (weeks) & $27.64 \pm 2.43$ \\
\hline Initial systolic blood pressure (mmHg) & $162.36 \pm 20.72$ \\
\hline Initial diastolic blood pressure (mmHg) & $105.62 \pm 12.46$ \\
\hline Pulse Rate & $87.94 \pm 4.39$ \\
\hline Table 1: Clinical Characteristics of Study Population \\
\hline
\end{tabular}

All patients achieved target blood pressure on the twice daily dose of medications; none required added other antihypertensive medications. The mean difference in the fall of the systolic/diastolic BP with Labetalol by one week was $10.74 / 6.48 \mathrm{mmHg}$ and by one month it was $18.72 / 13.79$ mmHg. There were no cases of eclampsia or imminent eclampsia during treatment.

\begin{tabular}{|c|c|c|}
\hline $\begin{array}{c}\text { Blood } \\
\text { Pressure }\end{array}$ & Outcome & Mean mmHg \\
\hline \multirow{2}{*}{ Systolic BP } & Fall in one week & $10.74 \mathrm{mmHg}$ \\
\cline { 2 - 3 } & Fall in one month & $18.72 \mathrm{mmHg}$ \\
\hline \multirow{2}{*}{ Diastolic BP } & Fall in one week & $6.48 \mathrm{mmHg}$ \\
\cline { 2 - 3 } & Fall in one month & $13.79 \mathrm{mmHg}$ \\
\hline \multicolumn{2}{|c|}{ Table 2: Comparison of Blood Pressure } \\
Control in the Study Group
\end{tabular}

On an individual assessment of the adverse effects like headache $(12 \%)$ is more common. Other adverse effects like 
pedal oedema (9\%), sweating (6\%), orthostatic hypotension (1\%), blurred vision (1\%) and facial oedema (1\%).

\begin{tabular}{|c|c|c|}
\hline $\begin{array}{c}\text { Side Effects } \\
\text { Observed }\end{array}$ & Number of Patients & Percentage \\
\hline Headache & 14 & $12.61 \%$ \\
\hline Pedal Oedema & 11 & $9.9 \%$ \\
\hline Sweating & 06 & $5.4 \%$ \\
\hline $\begin{array}{c}\text { Orthostatic } \\
\text { Hypotension }\end{array}$ & 03 & $2.7 \%$ \\
\hline Blurred Vision & 02 & $1.8 \%$ \\
\hline Facial Oedema & 10 & $9.0 \%$ \\
\hline \multicolumn{2}{|c|}{ Table 3: Side Effects of Labetalol } \\
Recorded During the Treatment \\
\hline
\end{tabular}

\section{DISCUSSION}

The Cochrane review on drugs for the treatment of high blood pressure in pregnancy concluded that until better evidence is available, the choice of antihypertensive should depend on the clinician's experience and familiarity with a particular drug. ${ }^{28}$

The appropriate selection of antihypertensive in preeclampsia is controversial in the literature. Most commonly preferred choice of antihypertensive is Labetalol, Methyldopa and Nifedipine in pre-eclampsia. ${ }^{29}$

As per the National Institute for Health and Clinical Excellence [NICE] guidelines for hypertension in pregnancy, the preferred choice of drug is oral labetalol to Nifedipine and Methyldopa. ${ }^{30}$

Labetalol is an alpha-blocker with nonselective betablocking properties. It is available in oral as well injectable forms. Its safety in the first trimester of pregnancy has been documented. ${ }^{31}$

A recent prospective study conducted by Nita K. Patela et al in $2012 .^{7}$ to evaluate the comparative effectiveness and safety of Nifedipine, Methyldopa and Labetalol monotherapy in patients with Pregnancy Induced Hypertension (PIH) concluded that Labetalol was more effective than Methyldopa and Nifedipine in controlling blood pressure in patients with Pregnancy Induced Hypertension (PIH). ${ }^{32}$

In the present study, efficacy was assessed based on control of blood pressure in 7 days and 1 month after treatment. There was no major adverse event attributed to drug regimen. It was found that Labetalol is effective in controlling blood pressure in moderate gestational pregnancy and is suitable first-line antihypertensive for hypertensive emergencies of pregnancy.

Our study showed that Labetalol significantly reduced systolic BP and diastolic BP by one month. There were no serious side effects in study period. Side effects of Labetalol were minimal and well tolerated. Headache $(12.61 \%)$ is more common as side effects, but none of the patients required addition treatment.

Based on our findings, we conclude that oral Labetalol could be used effectively and safely in the control of blood pressure in moderate gestational hypertension.

Limitation of our study was we did not include patients with severe hypertension in pregnancy, who had more chances of developing complications.

\section{CONCLUSION}

From our study, we observed that oral Labetalol is more efficacious in controlling blood pressure in patients with moderate gestational hypertension with less side effects. However, further study is needed to evaluate safety of these drugs during later stages of pregnancy, during labor and during postpartum period.

\section{REFERENCES}

1. Introduction to Preeclampsia. WHO recommendations for prevention and treatment of pre-eclampsia and eclampsia. WHO handbook for guideline development. Geneva, World Health Organization; 2010.

2. Report of the national high blood pressure education program working group on high blood pressure in pregnancy. Am J Obstet Gynaecol 2000;183(1):S1-S22.

3. Chauhan R, Sharma RS, Parashar MK, et al. Clinical examination of hypertension in pregnancy. In: Shah MR, editor. Hypertensive disorders in pregnancy. New Delhi: Jaypee Brothers Medical Publishers (P) Ltd; 2007;1 $1^{\text {st }}$ ed:111-25.

4. Magee LA, Helewa M, Moutquin JM, et al. Hypertension guideline committee. Strategic training initiative in research in the reproductive health sciences (STIRRHS) scholars. Diagnosis, evaluation, and management of the hypertensive disorders of pregnancy. J Obstet Gynaecol Can 2008;30(Suppl 3):S1-48.

5. National Institute for Health and Clinical Excellence (NICE). Hypertension in pregnancy: the management of hypertensive disorders during pregnancy. NICE clinical guideline 2010;107:1-295.

6. Lowe SA, Brown MA, Dekker GA, et al. Society of obstetric medicine of Australia and New Zealand (SOMANZ). Guidelines for the management of hypertensive disorders of pregnancy 2008. ANZJOG 2009;49(3):242-6. [www.somanz.org/guidelines.asp].

7. Martin JN, Thigpen BD, Moore RC, et al. Stroke and severe preeclampsia and eclampsia: a paradigm shift focusing on systolic blood pressure. Obstet Gynaecol 2005;105(2):246-54.

8. Cantwell R, Clutton-Brock T, Cooper G Saving, et al. Saving mothers lives: reviewing maternal deaths to make motherhood safer: 2006-08. The eighth report on confidential enquiries into maternal deaths in the United Kingdom. BJOG 2011;118(Suppl 1):1-203.

9. World Health Organization. WHO recommendations for prevention and treatment of pre-eclampsia and eclampsia. Geneva: WHO; 2011.

10. Magee LA, Ornstein MP, Von Dadelszen P. Management of hypertension in pregnancy. BMJ 1999;318:1332-6.

11. Magee LA, von Dadelszen P. The management of severe hypertension. Semin Perinatol 2009;33(3):138-42.

12. Magee L, Cham C, Waterman E, et al. Hydralazine for treatment of severe hypertension in pregnancy: metaanalysis. BMJ 2003;327:955-60.

13. Duley L, Henderson-Smart D, Meher S. Drugs for the treatment of very high blood pressure during pregnancy. Cochrane Database Syst Rev 2006;(3):CD001449.

14. PRISMA. Transparent reporting of systematic reviews and meta-analyses.

[www.prisma-statement.org/statement.htm]. Accessed 18 October 2012.

15. Dyakova M, Shantikumar S, Colquitt JL, et al. Systematic versus opportunistic risk assessment for the primary prevention of cardiovascular disease. Cochrane Database Syst Rev 2016. 
16. Tuzcu ZB, Asicioglu E, Sunbul M, et al. Circulating endothelial cell number and markers of endothelial dysfunction in previously preeclamptic women. Am J Obstet Gynaecol 2015;213(4):533.

17. Kulkarni R, Chauhan S, Daver R, et al. Prospective observational study of near-miss obstetric events at two tertiary hospitals in Mumbai, Maharashtra, India. Int J Gynaecol Obstet 2016;132(2):170-3.

18. Austdal M, Tangerås LH, Skrastad RB, et al. First trimester urine and serum metabolomics for prediction of preeclampsia and gestational hypertension: a prospective screening study. Int J Mol Sci 2015;16(9):21520-38.

19. Mvumbi L, Manci EA, Ulmer RD, et al. Decreased placental and umbilical cord glycogen levels associated with meconium-stained amniotic fluid. Placenta 1998;19(4):295-9.

20. Deedwania P. Evolving treatment options for prevention of cardiovascular events in high-risk hypertensive patients. J Clin Hypertens (Greenwich) 2007;9(11):883-8.

21. Ionescu DD. Antihypertensive efficacy of perindopril 5-10 $\mathrm{mg} /$ day in primary health care: an open-label, prospective, observational study. Clin Drug Investig 2009;29(12):767-76.

22. Rey E, LeLorier J, Burgess E, et al. Report of the Canadian hypertension society consensus conference: 3 . Pharmacologic treatment of hypertensive disorders in pregnancy. CMAJ 1997;157(9):1245-54.

23. Firoz T, Magee LA, MacDonell K, et al. Community level interventions for pre-eclampsia (CLIP) working group. Oral antihypertensive therapy for severe hypertension in pregnancy and postpartum: a systematic review. BJOG 2014;121(10):1210-8.

24. Yankowitz, Jerome. Pharmacological treatment of hypertensive disorders during pregnancy. Journal of Perinatal and Neonatal Nursing 2004;18(3):230-40.
25. Mishra AK, Verma SK, Kant S, et al. A study to compare the diagnostic efficacy of closed pleural biopsy with that of the thoracoscopic guided pleural biopsy in patients of pleural effusion. South Asian J Cancer 2016;5(1):27-8.

26. Nita K Patel, Mansi Gadhavi, Dhaval Gorasia, et al. Comparative evaluation of antihypertensive drugs in the management of pregnancy-induced hypertension. Int J Basic Clin Pharmacol 2012;1(3):174-7.

27. Safaeian L, Sajjadi SE, Javanmard SH, et al. Antihypertensive and antioxidant effects of hydroalcoholic extract from the aerial parts of Kelussia odoratissima Mozaff. in dexamethasone-induced hypertensive rats. Adv Biomed Res 2016;5:25.

28. Roberts JM, August PA. Prevention of preeclampsia. Hypertension in pregnancy report of American college of obstetricians and gynaecologists' task force on hypertension in pregnancy. Obstet Gynaecol 2013;122(5):1122-31. doi:10.1097/01.A0G.0000437382. 03963.88.

29. McCoy S, Baldwin K. Pharmacotherapeutic options for the treatment of preeclampsia. Am J Health Syst Pharm 2009;66(4):337-44. doi:10.2146/ajhp080104.

30. Fahed S, Grum DF, Papadimos TJ. Labetalol infusion for refractory hypertension causing severe hypotension and bradycardia: an issue of patient safety. Patient saf Surg 2008;2:13. DOI: 1186/1754-9493-2-13.

31. McDonald AJ, Yealy DM, Jacobson S. Oral labetalol versus oral nifedipine in hypertensive urgencies in the ED. Am J Emerg Med 1993;11(5):460-3.

32. El-Qarmalawi AM, Morsy AH, al-Fadly A, et al. Labetalol vs. methyldopa in the treatment of pregnancy-induced hypertension. Int J Gynaecol Obstet 1995;49(2):125-30. 